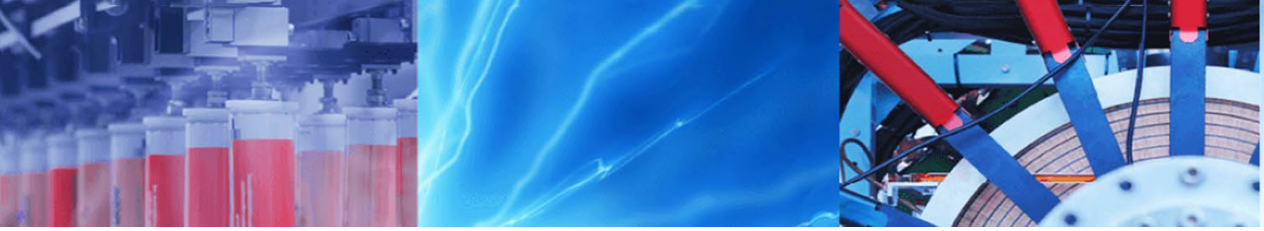

Case Study

\title{
Support vector regression approach with different kernel functions for predicting blast-induced ground vibration: a case study in an open-pit coal mine of Vietnam
}

\author{
Hoang Nguyen ${ }^{1,2}$ (i) \\ () Springer Nature Switzerland AG 2019
}

\begin{abstract}
Blast-induced ground vibration (PPV) is one of the effects of the hazard in open-pit mines. It can make vibration of the structure, instability of slope and bench, impact on underground water, and the surrounding residential. Therefore, the precise prediction of blast-induced PPV is needed to minimize undesirable effects on the surrounding environment. Also, one of the most important objectives of this study is to determine the site characteristics for the application of controlled blasting techniques. In this study, the support vector regression (SVR) approach was considered and developed for predicting blast-induced PPV in an open-pit coal mine (Vietnam) as a case study. Three forms of the equation include linear $(\mathrm{L})$, polynomial $(\mathrm{P})$, and radius basis function (RBF) were applied to develop the SVR models. For comparison purpose, an empirical technique was also referred to as estimate blast-induced PPV in this study on the same training dataset. A database with 181 blasting events was used for this aim. Performance indicators such as root-mean-square error (RMSE) and the coefficient of determination $\left(R^{2}\right)$ were used to compare and evaluate the performance of the predictive models. The results showed that SVR was an effective approach for predicting blast-induced PPV in this study. Among three forms of the equation, the SVR model with RBF was the most superior model for predicting blast-induced PPV in this study with an RMSE of $0.396, R^{2}$ of 0.924 , and MAE of 0.135 , whereas the empirical model only obtained performance with an RMSE of $0.856, R^{2}$ of 0.643 , and MAE of 0.575 . This study provided an overview of the SVR approach in predicting blast-induced PPV. A comparison of different kernel functions for the selection of the SVR model is needed to find out the best model for predicting blast-induced PPV.
\end{abstract}

Keywords Support vector regression · Empirical · Blasting · Ground vibration · Open-pit mine · Vietnam

\section{Introduction}

Open-pit mining is a type of technology that recovers resources in the ground, including drilling, blasting, loading, and hauling operations [1]. The mining process usually removes the burden for exposing the mineral deposits or fragment hard rock for subsequent operations (loading, transporting, or dumping). And one of the most effective methods is still blasting. For fragmenting rocks by the drilling-blasting method, the boreholes with various diameters $(45-250 \mathrm{~mm}$ ) were used. Then, the explosive was charged in the boreholes. The other blasting accessories such as blasting cap, detonator fuse, detonating primer, and signal tube can be used to detonate boreholes [2]. When initiated, the energy of the explosives will strike and break the rock. However, not $100 \%$ of explosives energy was used to break rock [3]. According to previous scientists, up to $80-85 \%$ of the energy of explosives was wasted and produced ill effects, such as ground vibration (PPV), air overpressure, fly rock,

\footnotetext{
$\triangle$ Hoang Nguyen, nguyenhoang@humg.edu.vn | ${ }^{1}$ Department of Surface Mining, Mining Faculty, Hanoi University of Mining and Geology, 18 Vien Str., Duc Thang Ward, Bac Tu Liem Distr., Hanoi, Vietnam. ${ }^{2}$ Center for Mining, Electro-Mechanical Research, Hanoi University of Mining and Geology, 18 Vien St., Duc Thang Ward, Bac Tu Liem Dist., Hanoi, Vietnam.
}

SN Applied Sciences (2019) 1:283 | https://doi.org/10.1007/s42452-019-0295-9

Received: 28 November 2018 / Accepted: 21 February 2019 / Published online: 1 March 2019 
dust and toxic [4-8]. Of these side effects, ground vibration is the most dangerous effect [9-11]. It can make quake and destroy the surrounding structures, instability of the slope and benches, effects on the railway, underground water, etc., (Fig. 1). Therefore, the accurate blastinduced PPV prediction is required for a few reasons as follows:

- Ensuring that levels of vibration do not cause damage to neighboring property;

- Preventing annoyance to others by maintaining the lowest possible levels;

- Demonstrating compliance with conditions;

- Reducing the undesirable effects on the environment.

For predicting blast-induced PPV, the parameters' influence is investigated and defined. There are many parameters that influence blast-induced PPV, including the controllable and uncontrollable parameters [12-14]. Of the two group parameters, the controllable parameters may include (but not limit) the following parameters: maximum charge per delay $(W)$, monitoring distance $(R)$, spacing $(S)$, powder factor $(P)$, burden $(B)$, bench height $(H)$, stemming $(T)$, blast-hole depth $(L)$. The blast designers can change these parameters [15]. In the uncontrollable parameters group, parameters related to geological and geophysical conditions are parameters that cannot be altered by blast designers such as rock hardness, crack, bedding, faults, density distribution [16]. Thus, PPV-blast-induced predictive studies usually focus on the controllable parameters by blast designers. Of the controllable parameters, the maximum charge per delay $(W)$ and monitoring distance $(R)$ was the most influential parameters for blast-induced PPV [17-20].

With the estimation of blast-induced PPV, many scholars have attempted to study and develop empirical formulas based on the relationship between $W$ and $R$ as shown

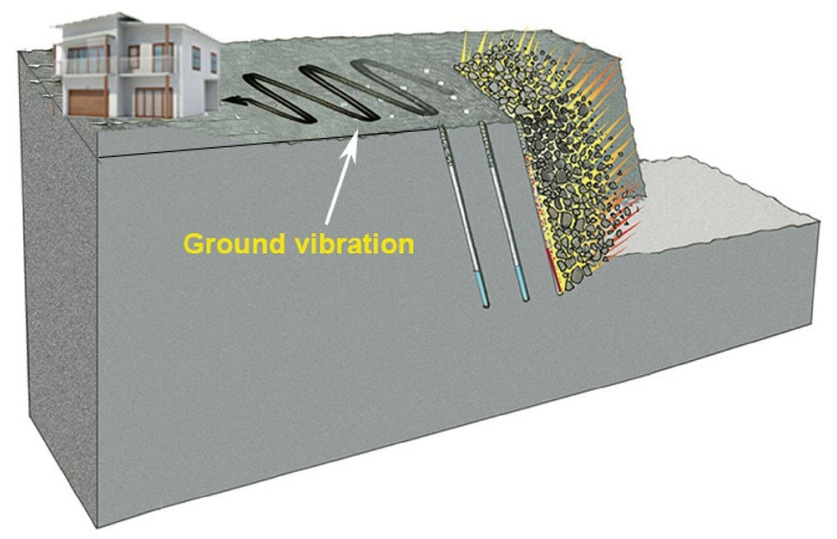

Fig. 1 Blast-induced ground vibration for rock fragmentation in Table 1. Nevertheless, their effectiveness is not high in some cases [7, 17, 18, 21-23].

In recent years, artificial intelligence (AI) has become more popular and widely applied in many different fields. Review of literature showed that $\mathrm{Al}$ had been involved in many aspects such as mineralizing geochemical anomalies [33-35], optimizing operational mine planning [36], civil engineering [37, 38], analyzing mineral systems [39], mineral potential mapping $[40,41]$, resourcing future generations $[42,43]$, predicting blast-induced problems [44-47]. In predicting blast-induced PPV, the feasibility of a support vector machine (SVM) algorithm was studied and applied by Hasanipanah et al. [7] to predict blast-induced PPV in Bakhtiari Dam, Iran. A total of 80 blasts were used in their study with 60 blasting events for the training process and 20 blasts for the testing process. A variety of empirical equations were used by Hasanipanah et al. [7] to estimate PPV and compare with the SVM model. The performance of the predictive models was evaluated based on a series of criteria such as variance absolute relative error (VARE), root-mean-square error (RMSE), determination coefficient $\left(R^{2}\right)$, median absolute error (MEDAE), mean absolute percentage error (MAPE), Nash and Sutcliffe (NS), and variance accounted for (VAF). Based on the results, they indicated that SVM model provided higher performance capacity in predicting blast-induced PPV compared to empirical equations with an RMSE of $0.34, R^{2}$ of 0.957 , VARE of 0.3 , MAPE of 6.36 , MEDAE of 0.15 , NS of 0.94 , and VAF of 94.24 . In another study, [6] successfully developed the blastinduced PPV predictive model based on an artificial neural

Table 1 Some empirical techniques for predicting PPV proposed

\begin{tabular}{lll}
\hline No. & References & Empirical equation \\
\hline 1 & Duvall and Petkof [24] & $P P V=k\left(\frac{R}{\sqrt{W}}\right)^{-b}$ \\
2 & $\begin{array}{c}\text { Langefors and Kihlstrom } \\
\text { [25] }\end{array}$ & $P P V=k\left(\frac{W}{R^{\frac{2}{3}}}\right)^{\frac{b}{2}}$ \\
3 & Ambraseys [26] & $P P V=k\left(\frac{R}{\sqrt[3]{W}}\right)^{-b}$ \\
4 & Ghosh and Daemen [27] & $P P V=k\left(\frac{R}{\sqrt{W}}\right)^{-b} e^{-\alpha R}$ \\
5 & Roy [28] & $P P V=n+k\left(\frac{R}{\sqrt{W}}\right)^{-1}$ \\
6 & Ak and Konuk [29] & $P P V=k\left(\frac{R}{\sqrt{W}}\right)^{-b} \lambda^{\alpha}$ \\
7 & Simangunsong and & $P P V=k\left(\left(1+\cos \theta_{i}+N_{c}\right) \frac{R}{\sqrt{W}}\right)^{-b}$ \\
8 & Wahyudi [30] & $P P V=\frac{f_{c}^{0.642} D^{-1.463}}{\gamma}$ \\
9 & Murmar et al. [31] & $P P V=k\left(\frac{R}{W^{\frac{2}{5}}}\right)^{-b}$
\end{tabular}


network and K-nearest neighbor algorithm, i.e., ANN-KNN. Seventy-five blasting events with two input variables, $W$ and $D$, were used for predicting PPV in their study. An empirical equation of the United States Bureau of Mines (USBM) was also performed for estimating blast-induced PPV. RMSE, $R^{2}$, and VAF are the performance indices used for assessment of the quality of the models in their study. As a result, they found the optimal ANN-KNN model with an RMSE of $0.54, R^{2}$ of 0.88 , and VAF of 87.84. In another algorithm, Hasanipanah et al. [48] developed a simple model with high precision to predict the PPV produced by blasting using particle swarm optimization (PSO) with two forms of the equation, including linear and power. The two input variables, $W$ and $D$, were also identified by Hasanipanah et al. [48] and used as input parameters for predicting PPV. The USBM experimental technique is a comparative method used to evaluate the effectiveness of the PSO model in their study. A great conclusion is given by Hasanipanah et al. [48] that a PSO model with power equation provided a higher accuracy than the USBM model for forecasting PPV with an RMSE of 0.24 and $R^{2}$ of 0.938 . In another study, Hasanipanah et al. [49] developed a classification and regression tree (CART) model to predict PPV in an open-pit mine. Eighty-six blasting events were monitored for their study. An effort for building a CART model was conducted with a good result, RMSE of 0.17 and $R^{2}$ of 0.95. In a new survey, Armaghani et al. [50] investigated and studied the usability of the imperialist competitive algorithm (ICA) for predicting blast-induced PPV with two forms of equations, i.e., power and quadric. Seventy-three blasting events were collected for their aim with $W, D$ and $P P V$ being carefully measured. As a result, the ICA quadratic form is the most dominant model among the developed models with an RMSE of 0.37 and $R^{2}$ of 0.94 . Several similar works can be found at those references [51-55].

Review of the literature showed that SVR had been successfully implemented for blasting problems in several places [7, 56-59]. Nevertheless, it has not been applied in all areas. However, the effects of blast-induced PPV in each country are different [60] and need to be accurately predicted. Also, comparison, evaluation, and selection of SVR models with varying functions of kernel have not been performed in previous studies. Review of literature showed that Hasanipanah et al. [7] evaluated the feasibility of SVR for predicting blast-induced PPV. However, it seems they have specified the radial primary kernel function (RBF) for the development of the SVR model. Also, Sheykhi et al. [44] also developed the SVR models based on fuzzy C-means clustering (FCM). The RBF was also selected as a kernel function for the development of their study without comparison and evaluation. Hence, SVR models were developed in this study with three forms of kernel function for predicting blast-induced PPV. Comparison and assessment of them are employed for the determination of the best SVR model in this study.

The structure of the article consists of six parts as follows: Sect. 1 presents the reason to implement this study and overview of related works; Sect. 2 describes the study area and data used as a case study; Sect. 3 shows the background of the methodology used; the blast-induced PPV prediction model is developed in Sect. 4; Sect. 5 demonstrates and discusses the results of this work; finally, the conclusions and recommendations are given.

\section{Study area and data used}

\subsection{Study area}

The study area is medium mountainous with an absolute altitude in a range of $100-434 \mathrm{~m}$. The mine in the form of plain terrain has an elevation of 50-100 meters over the sea level. It is located between longitude $105^{\circ} 30^{\prime} 40^{\prime \prime} \mathrm{E}$ and $105^{\circ} 31^{\prime} 00^{\prime \prime} \mathrm{E}$, and latitude $21^{\circ} 42^{\prime} 30^{\prime \prime} \mathrm{N}$ and $21^{\circ} 43^{\prime} 00^{\prime \prime} \mathrm{N}$ (Fig. 2). The geological composition of the study area is involved, including faults and layers of metamorphic sandstone, zander, limestone, shale, and siltstone. The thickness of the coal seam varies from 0 to $2.75 \mathrm{~m}$; overburden is in a range of 5-10.2 m.

The mine's reserves are 945,900 tons. Annual mining output is $80,000-100,000$ tons/year. The maximum depth of the mine is $-202 \mathrm{~m}$, and the height of the slope is $245-270 \mathrm{~m}$ with the slope angle changing from $32^{\circ}$ to $36^{\circ}$. The rock mass has a relatively high hardness (pebbles, gravel, clay), and the drilling-blasting method was applied to rock breakage. The mine uses two main diameters of $220 \mathrm{~mm}$ and $105 \mathrm{~mm}$ for boreholes. Explosives are mainly used by ANFO and AD-1 with non-electric delay blasting. In the overburden benches, the maximum charge per delay was in a range of $100-623 \mathrm{~kg}$.

\subsection{Described data used}

As discussed in Sect. 1, the maximum charge per delay $(W)$ and monitoring distance $(R)$ were the most influential parameters for blast-induced PPV. Therefore, $W$ and $R$ are two parameters used to predict blast-induced PPV in this study. The datasets used in this study are summarized in Table 2.

From Table 2, it can be seen that $W$ is in a range of $100-623 \mathrm{~kg}, R$ is in the range of $48-218 \mathrm{~m}$, and PPV was recorded in the range of 17.21-23.55. For collecting the datasets, Micromate instrument (Instantel-Canada) was used to record blast-induced PPV. PPV can be recorded in the range of $0.127-254 \mathrm{~mm} / \mathrm{s}$ by the Micromate instrument. A handheld GPS navigation system was used to 


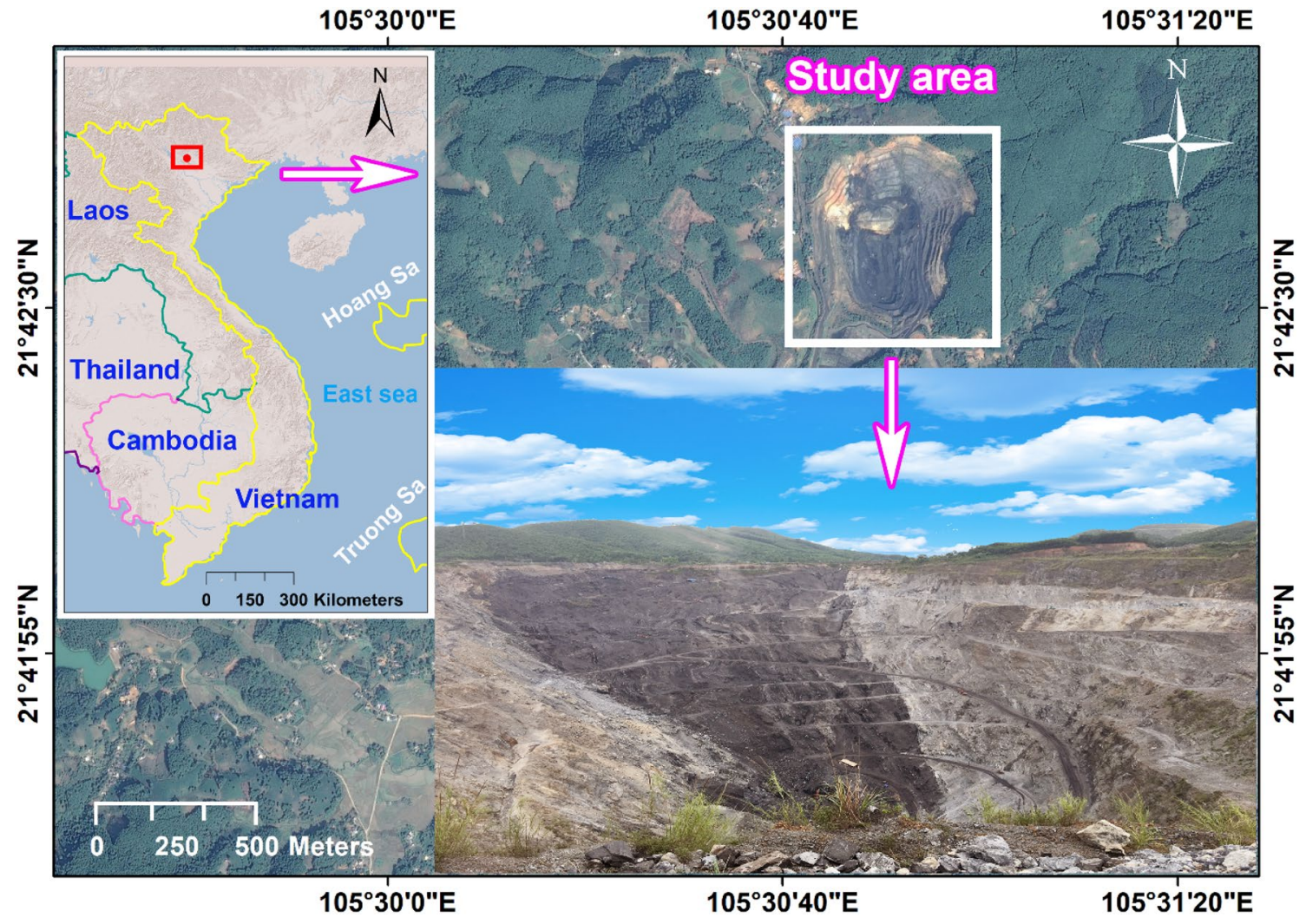

Fig. 2 A view of the site study

Table 2 Summary of the datasets used in this study

\begin{tabular}{lll}
\hline$W$ & $R$ & PPV \\
\hline Min. 100.0 & Min. 48.0 & Min. 17.21 \\
1st Qu. 237.0 & 1st Qu. 110.0 & 1st Qu. 19.88 \\
Median 316.0 & Median 133.0 & Median 20.59 \\
Mean 318.9 & Mean 134.2 & Mean 20.60 \\
3rd Qu. 397.0 & 3rd Qu. 154.0 & 3rd Qu. 21.50 \\
Max. 623.0 & Max. 218.0 & Max. 23.55 \\
\hline
\end{tabular}

determine monitoring distance $(R)$. Finally, $W$ was collected from blasts design. Figure 3 illustrates a histogram of the datasets collected in this study.

\section{Overview of support vector regression with kernel functions}

Support vector machine (SVM) is a machine learning algorithm based on the principle of minimizing structural risk to generalize a limited number of samples better and is proposed by Cortes, Vapnik [61]. SVM can solve both classification and regression problems. For regression problems, the SVM is called the support vector regression (SVR). SVR relies on a subset of training datasets to build the forecasting model [62]. The goal of SVR is to estimate a smooth function $f(X)$ with a deviation not more significant than $\varepsilon$ for all output values [63].

For predicting blast-induced PPV in this study, SVR is performed based on three forms of kernel function as follows:

- Linear kernel:

$$
K(X, Y)=X^{\top} Y
$$

- Polynomial kernel:

$$
K(X, Y)=\left(\gamma \cdot X^{T} Y+r\right)^{d} ; \quad \gamma>0 ; d=(1,2, \ldots)
$$

- Radial primary kernel function:

$$
K(X, Y)=\exp \left[\frac{\|X-Y\|^{2}}{2 \sigma^{2}}\right]
$$

Here $r, d, \gamma$, and $\sigma$ are kernel parameters which can be adjusted for optimal predictive models. In addition to the parameters of the algorithm, $C$ parameter (cost) is also a penalty factor used to improve the accuracy of the predictive models [64].

\section{SN Applied Sciences}


Fig. 3 Histogram of the datasets used in this study

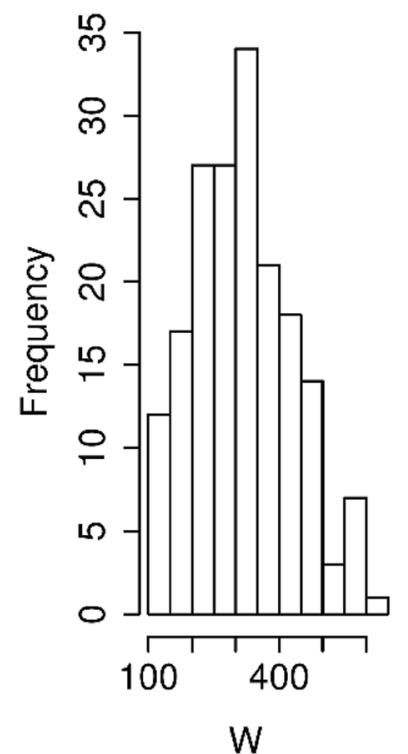

\section{Proposing SVR models with different kernel functions for predicting PPV}

To develop the SVR models, the original datasets were divided into two parts, $85 \%$ of the whole datasets ( 157 blasting events) were used as the training datasets, and the rest $15 \%$ (24 blasting events) were used as the testing datasets. It should be noted that all the PPV predictive models are developed based on the same training datasets and validated based on the same testing datasets.
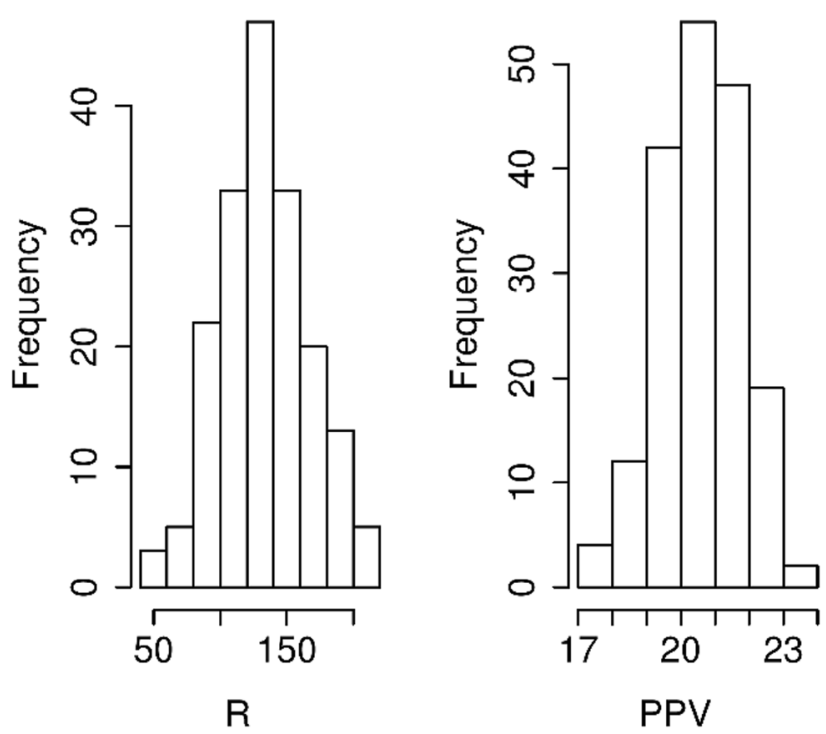

\subsection{Support vector regression with linear (SVR-L)}

For support vector regression with linear (SVR-L), no parameters of kernel functions are used to optimize the model. Only the $C$ penalty factor is adjusted to improve the accuracy of the SVR-L model. For increasing the accuracy of the model and avoid overfitting, tenfold cross-validation resampling technique with three repeats was used in the development of the SVR-L models. A "trial and error" procedure was performed with 1000 SVR-L models for various $C$ parameter values as shown in Fig. 4. Root-mean-square error (RMSE) was used to select the optimal model using the smallest value. As a result, the final value used for the model was $C=0.18$.
Fig. 4 Performance of SVR-L models on the training datasets

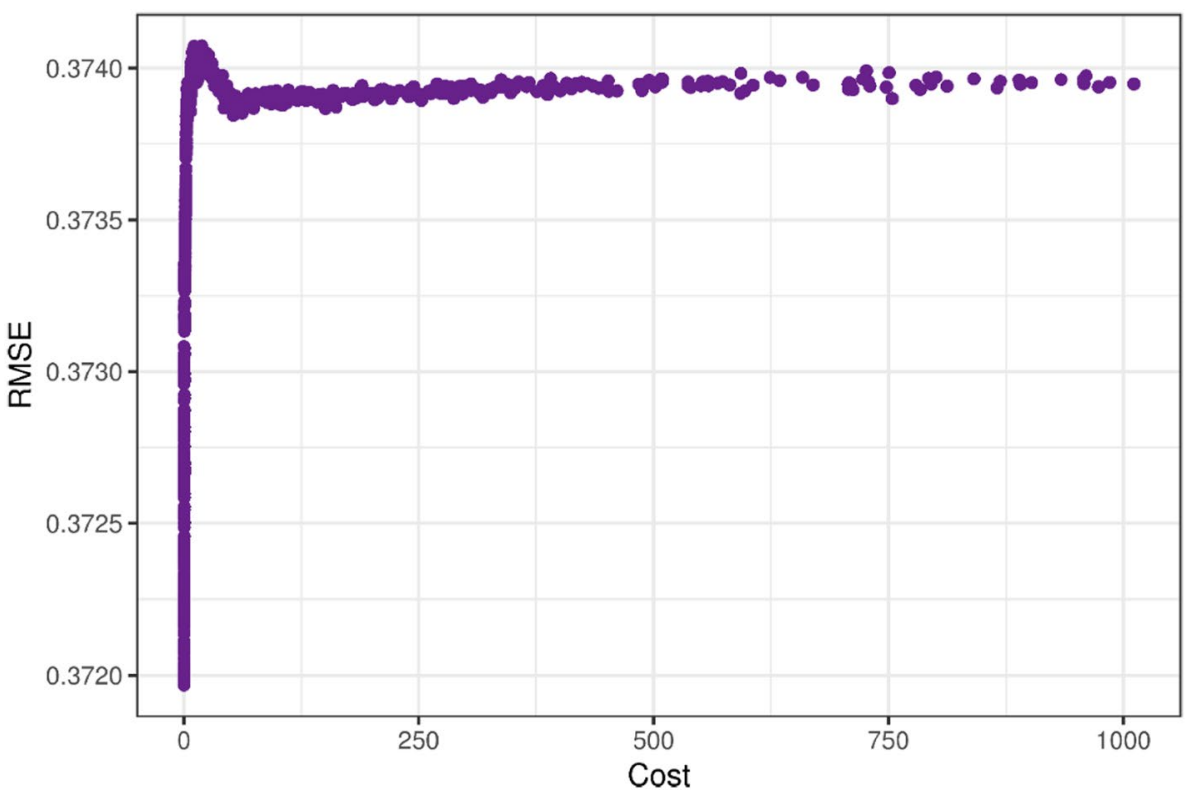

SN Applied Sciences 


\subsection{Support vector regression with radial basis function (SVR-RBF)}

In support vector regression with radial basis function (SVR-RBF), there are two parameters that can be adjusted to optimize the predictive model, including $\sigma$ and $C$. Like the SVR-L models, a "trial and error" procedure is also employed with 1000 SVR-RBF models for variables $\sigma$ and $C$ parameters. Tenfold cross-validation resampling technique with three repeats was also used in the development of the SVR-RBF models for increasing the accuracy of the model and avoid overfitting. RMSE continues to be used to select the optimal model using the smallest value. The final values used for the SVR-RBF model were $\sigma=0.017$ and $C=304.411$. Figure 5 illustrates the performance of SVR-RBF models with various parameters.

\subsection{Support vector regression with polynomial (SVR-P)}

In support vector regression with polynomial (SVR-P), there are three parameters used for controlling the performance of the model, including degree, scale, and C. Similar to the SVR-L and SVR-RBF models, a "trial and error" procedure with 1000 models was developed for SVR-P models. For improving the accuracy of the model and avoid overfitting, tenfold cross-validation resampling technique with three repeats was used in the development of the SVR-P models. RMSE was used to select the optimal model using the smallest value. As a result, the final values used for the model were degree $=3$, scale $=0.117$ and $C=0.08$ as shown in Fig. 6.

\section{Results and discussion}

\subsection{Performance metrics for evaluating the models}

To assess the performance of the mentioned predictive models, the performance indicators are used, including root-mean-square error (RMSE), coefficient of determination $\left(R^{2}\right)$, and mean absolute error (MAE), which are calculated using Eqs. (4-6), respectively.

$R M S E=\sqrt{\frac{1}{n} \sum_{P P V=1}^{n}\left(y_{P P V}-\hat{y}_{P P V}\right)^{2}}$

$R^{2}=1-\frac{\sum_{P P V}\left(y_{P P V}-\hat{y}_{P P V}\right)^{2}}{\sum_{P P V}\left(y_{P P V}-\bar{y}\right)^{2}}$

$M A E=\frac{1}{n} \sum_{P P V=1}^{n}\left|y_{P P V}-\hat{y}_{P P V}\right|$

where $n$ is the total number of data; $y_{P P V}$ is the measured value, $\hat{y}_{P P V}$ is the predicted value; and $\bar{y}$ is mean of measured values. In the most optimal model, $R^{2}$ should be equal to 1 , and RMSE and MAE should be similar to 0 , respectively.

\subsection{Empirical}

For comparison and evaluation of the performance of the predictive models, an empirical technique is also applied
Fig. 5 Performance of SVRRBF models on the training datasets

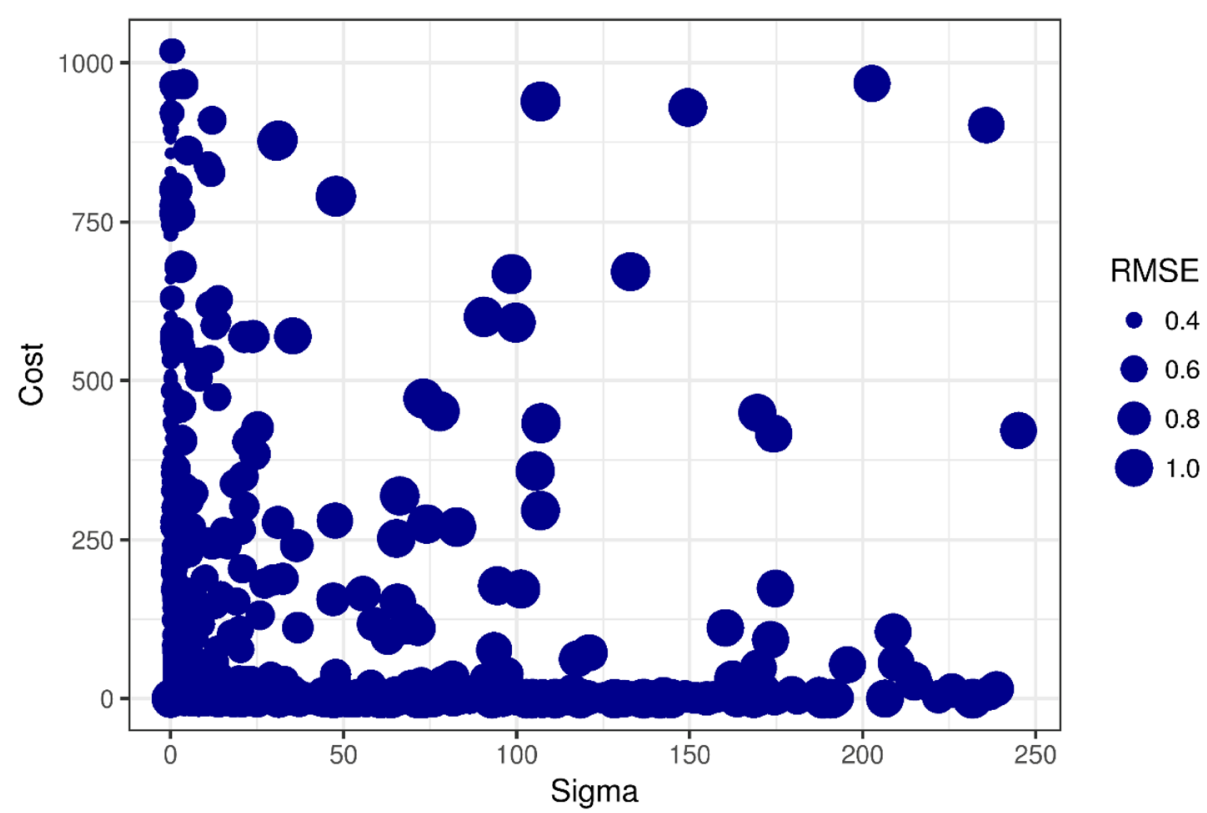


Fig. 6 Performance of SVR-P models on the training datasets
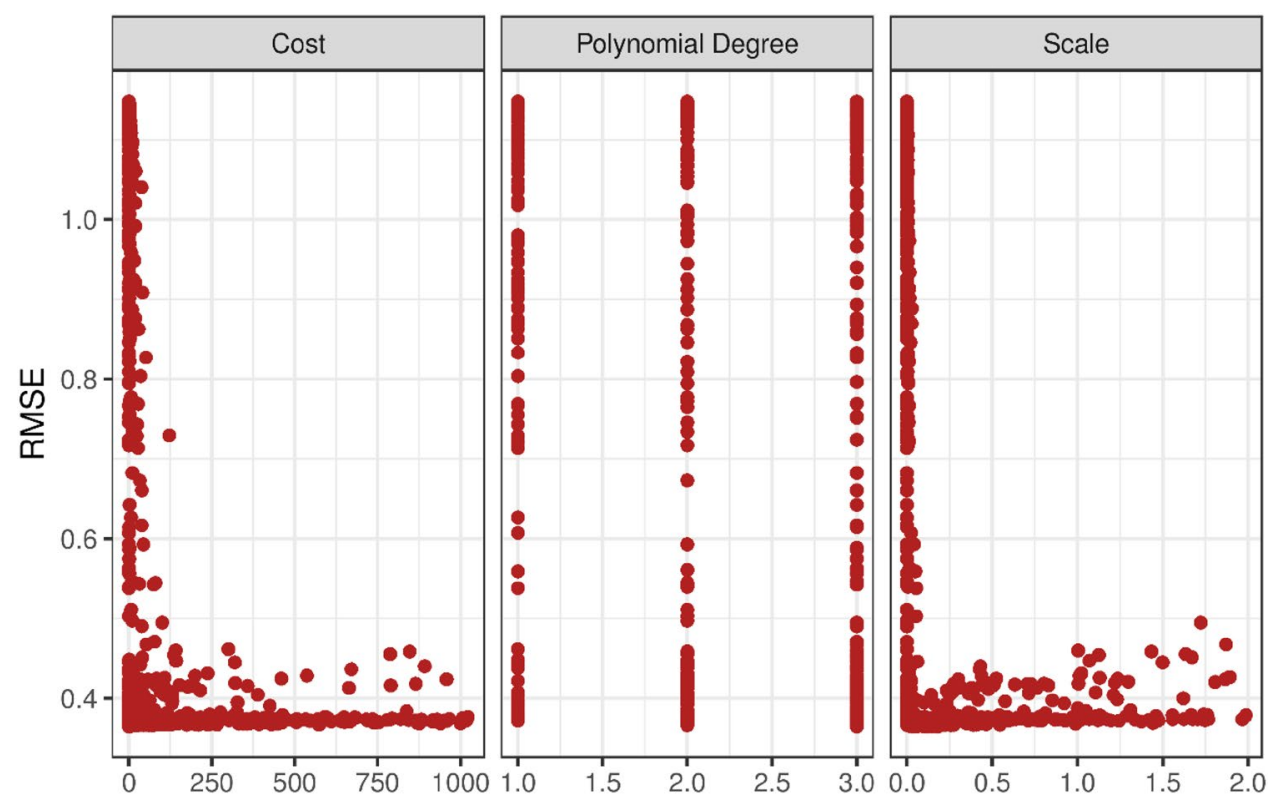

in this study. Of the current empirical methods, the United States Bureau of Mines (USBM) remained the most widely used empirical method for estimating PPV and was proposed by Duvall, Petkof [24]. Therefore, we have chosen a USBM innovative formula that represents experimental techniques to evaluate blast-induced PPV in this study. The USBM empirical method is described in Eq. 7 as follows:

$P P V=\lambda\left(\frac{R}{\sqrt{W}}\right)^{-\alpha}$

where $W$ is the maximum charge per delay, $\mathrm{kg} ; R$ is the distance between the blast site and monitoring point, $\mathrm{m}$; $\lambda$ and $\alpha$ are the site factors and are determined by the multivariate regression analysis.

According to Eq. $7, \lambda$ and $a$ are the site factors and are determined by the multivariate regression analysis. It should be noted that 157 blasting events in the training datasets are used to identify the site factors $\lambda$ and $a$. SPSS version 18.0 [65] is used for multivariate regression analysis to determine the site factors $\lambda$ and $a$. As a result, $\lambda$ and $\alpha$ identified 67.054 and 0.585 , respectively. The USBM empirical technique for estimating blast-induced PPV in this study was defined according to Eq. (7) as follows:

$P P V=67.054\left(\frac{R}{\sqrt{W}}\right)^{-0.585}$

\subsection{Comparison and assessment of the predictive models}

Based on the developed predictive models, the testing datasets are used to evaluate the performance of the models via metrics in Eqs. (4-6). Accordingly, RMSE, $R^{2}$, and MAE are calculated on both the training and testing datasets. Table 3 interprets the performance of the models.

From Table 3, it can be seen that the empirical technique (USBM) provided the lowest performance on both the training and testing datasets. On the testing datasets, the empirical only reached an RMSE of $0.856, R^{2}$ of 0.643 , and MAE of 0.575 , whereas the SVR models, i.e., SVR-L, SVRRBF, and SVR-P, yielded much higher performance than the empirical. It can be seen that the SVR models seem to work better for predicting blast-induced PPV. Of the three SVR models, SVR-RBF was the best model with an RMSE of
Table 3 Performance of the PPV predictive models on training and testing datasets

\begin{tabular}{llllllll}
\hline Model & \multicolumn{2}{l}{ Training datasets } & & \multicolumn{3}{l}{ Testing datasets } \\
\cline { 2 - 3 } & RMSE & $R^{2}$ & MAE & & RMSE & $R^{2}$ & MAE \\
\hline Empirical & 0.771 & 0.561 & 0.515 & & 0.856 & 0.643 & 0.575 \\
SVR-L & 0.372 & 0.857 & 0.183 & & 0.415 & 0.915 & 0.156 \\
SVR-RBF & 0.368 & 0.855 & 0.184 & & 0.396 & 0.924 & 0.135 \\
SVR-P & 0.365 & 0.857 & 0.189 & & 0.412 & 0.916 & 0.157 \\
\hline
\end{tabular}


$0.396, R^{2}$ of 0.924 , and MAE of 0.135 on the testing datasets. Based on the obtained results, it can be seen that the controlled blasting techniques can be effectively applied by Al techniques, i.e., SVR models. However, they depend on the characteristics of each site. Therefore, they can be reconsidered when asked for another location. Figure 7 demonstrates the proper scale of the predictive models for predicting blast-produced PPV in this study.

To assess the certain level of the predictive models, the predicted values were compared to measured values on the testing datasets and are shown in Table 4. Accordingly, it can be seen that the SVR-RBF model yielded the predicted values which closer the measured values than the other models. With high levels of accuracy, the SVR-RBF model can be applied to control the hazards caused by blasting operations in open-pit mines and minimizing the impacts on the environment.

\section{Conclusions and recommendations}

As an indispensable development, blasting is still the most popular and effective method for rock fragmentation in an open-pit mine. However, safety and sustainable development in mining are essential requirements for the mining industry. Therefore, the undesirable effects caused by blasting operations in open-pit mine need to be strictly controlled, especially ground vibration. This study investigated and developed a series of blast-induced PPV prediction models based on the SVR algorithm with three different kernel functions. Comparison and assessment of them were implemented with the USBM empirical technique. Finally, the best model for predicting blast-induced PPV
Table 4 Comparison of measured and predicted values of the predictive models on testing datasets

\begin{tabular}{llllll}
\hline No. & Measured & Empirical & SVR-L & SVR-RBF & SVR-P \\
\hline 1 & 21.00 & 24.26 & 22.97 & 22.91 & 22.97 \\
2 & 18.13 & 19.39 & 18.41 & 18.13 & 18.24 \\
3 & 21.17 & 20.91 & 21.20 & 21.20 & 21.17 \\
4 & 19.97 & 20.26 & 20.05 & 20.06 & 20.08 \\
5 & 19.53 & 19.82 & 19.51 & 19.53 & 19.54 \\
6 & 19.03 & 19.37 & 19.03 & 19.04 & 19.02 \\
7 & 22.79 & 22.45 & 22.76 & 22.71 & 22.74 \\
8 & 19.97 & 20.20 & 20.06 & 20.09 & 20.10 \\
9 & 19.90 & 20.12 & 19.93 & 19.95 & 19.97 \\
10 & 21.80 & 21.39 & 21.79 & 21.78 & 21.73 \\
11 & 17.82 & 18.85 & 18.07 & 17.75 & 17.79 \\
12 & 21.27 & 21.00 & 21.26 & 21.26 & 21.23 \\
13 & 19.15 & 19.48 & 19.07 & 19.06 & 19.06 \\
14 & 20.19 & 20.35 & 20.30 & 20.32 & 20.33 \\
15 & 18.74 & 19.43 & 18.93 & 18.89 & 18.90 \\
16 & 22.80 & 23.93 & 22.92 & 22.86 & 22.91 \\
17 & 21.65 & 21.17 & 21.66 & 21.67 & 21.62 \\
18 & 21.07 & 20.54 & 21.04 & 21.08 & 21.03 \\
19 & 21.50 & 21.22 & 21.41 & 21.40 & 21.37 \\
20 & 22.00 & 21.34 & 21.95 & 21.95 & 21.90 \\
21 & 20.93 & 20.53 & 20.88 & 20.92 & 20.88 \\
22 & 20.49 & 20.61 & 20.55 & 20.55 & 20.57 \\
23 & 21.98 & 21.41 & 21.90 & 21.89 & 21.84 \\
24 & 20.39 & 20.64 & 20.47 & 20.46 & 20.48 \\
\hline & & & & &
\end{tabular}

in Phan Me open-pit coal mine, Vietnam, was selected, i.e., SVR-RBF.

In conclusion, SVR is a robust algorithm for predicting blast-induced PPV with the power of kernel functions.
Fig. 7 The relationship between measured and predicted values of the predictive models on testing datasets
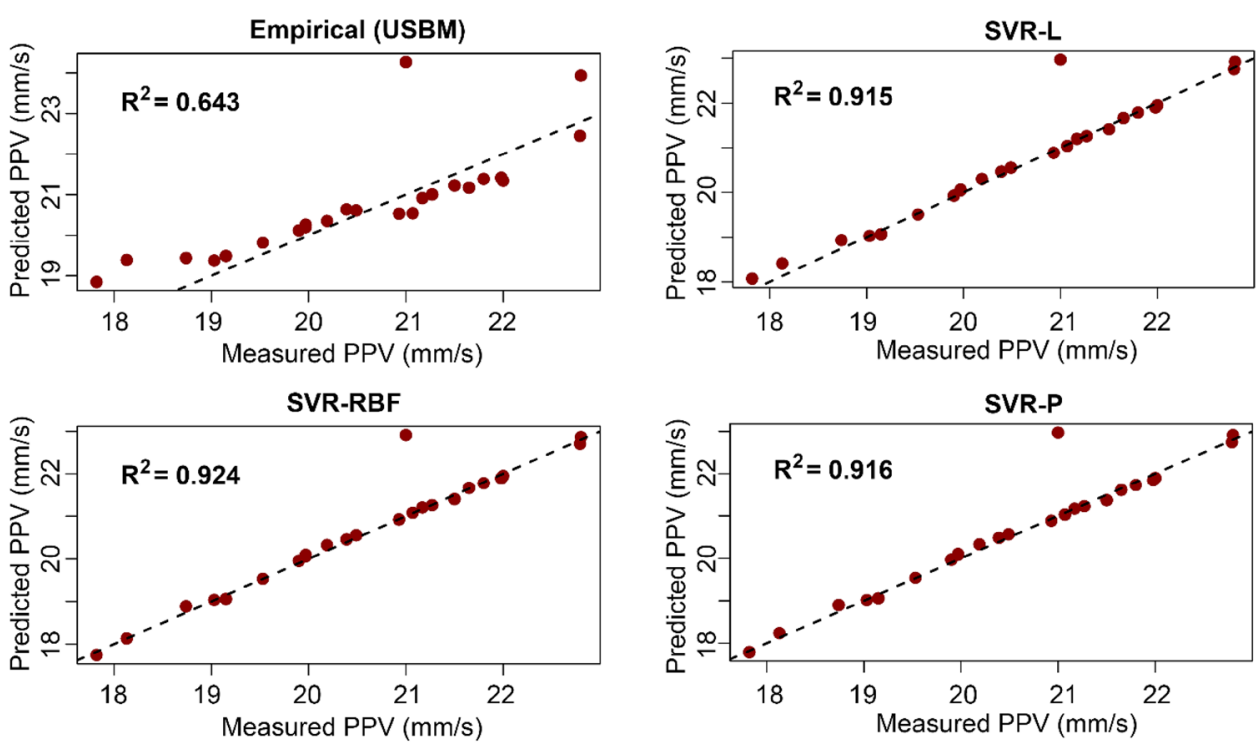
In this study, the SVR model with RBF form seems to be more appropriate than $L$ and $P$ functions in predicting blast-induced PPV in this area. With high accuracy, the results indicated that the SVR-RBF model should be applied in practical engineering to control the impacts of PPV on the surrounding environment. The remaining SVR models may also be considered in other mine conditions and should be further investigated to improve the accuracy of the model.

Acknowledgements This research was supported by Hanoi University of Mining and Geology (HUMG) and the Center for Mining, ElectroMechanical research of HUMG.

\section{Compliance with ethical standards}

Conflict of interest The authors declare that they have no conflict of interest.

\section{References}

1. Bakhtavar E, Mahmoudi H (2018) Development of a scenariobased robust model for the optimal truck-shovel allocation in open-pit mining. Comput Oper Res

2. Bach NV, Nam BX, An ND, Hung TK (2012) Determination of blast-induced ground vibration for non-electric delay blasting (in Vietnamse). J Sci Technol Hanoi Univ Min Geol 38:25-28

3. Bakhtavar E, Nourizadeh H, Sahebi A (2017) Toward predicting blast-induced flyrock: a hybrid dimensional analysis fuzzy inference system. Int J Environ Sci Technol 14(4):717-728

4. Khandelwal M, Singh T (2005) Prediction of blast induced air overpressure in opencast mine. Noise Vib Worldw 36(2):7-16

5. Trivedi R, Singh T, Gupta N (2015) Prediction of blast-induced flyrock in opencast mines using ANN and ANFIS. Geotech Geol Eng 33(4):875-891

6. Amiri M, Amnieh HB, Hasanipanah M, Khanli LM (2016) A new combination of artificial neural network and K-nearest neighbors models to predict blast-induced ground vibration and air-overpressure. Eng Comput 32(4):631-644

7. Hasanipanah M, Monjezi M, Shahnazar A, Armaghani DJ, Farazmand A (2015) Feasibility of indirect determination of blast induced ground vibration based on support vector machine. Measurement 75:289-297

8. Armaghani DJ, Hasanipanah M, Mohamad ET (2016) A combination of the ICA-ANN model to predict air-overpressure resulting from blasting. Eng Comput 32(1):155-171

9. Mines USBo, Siskind D (1980) Structure response and damage produced by ground vibration from surface mine blasting. US Department of the Interior, Bureau of Mines New York

10. Kahriman A (2004) Analysis of parameters of ground vibration produced from bench blasting at a limestone quarry. Soil Dyn Earthq Eng 24(11):887-892

11. Duvall WI, Fogelson DE (1962) Review of criteria for estimating damage to residences from blasting vibrations. US Department of the Interior, Bureau of Mines

12. Singh T, Singh V (2005) An intelligent approach to prediction and control ground vibration in mines. Geotech Geol Eng 23(3):249-262
13. Singh T, Verma $A$ (2010) Sensitivity of total charge and maximum charge per delay on ground vibration. Geomat Nat Hazards Risk 1(3):259-272

14. Verma A, Singh T (2013) Comparative study of cognitive systems for ground vibration measurements. Neural Comput Appl 22(1):341-350

15. Bui X-N, Nguyen H, Le H-A, Bui H-B, Do N-H (2019) Prediction of blast-induced air over-pressure in open-pit mine: assessment of different artificial intelligence techniques. Nat Resour Res. https ://doi.org/10.1007/s11053-019-09461-0

16. Nguyen H, Bui X-N (2018) Predicting blast-induced air overpressure: a robust artificial intelligence system based on artificial neural networks and random forest. Nat Resour Res. https://doi. org/10.1007/s11053-018-9424-1

17. Monjezi M, Ghafurikalajahi M, Bahrami A (2011) Prediction of blast-induced ground vibration using artificial neural networks. Tunn Undergr Space Technol 26(1):46-50

18. Monjezi M, Hasanipanah M, Khandelwal M (2013) Evaluation and prediction of blast-induced ground vibration at Shur River Dam, Iran, by artificial neural network. Neural Comput Appl 22(7-8):1637-1643

19. Armaghani DJ, Momeni E, Abad SVANK, Khandelwal M (2015) Feasibility of ANFIS model for prediction of ground vibrations resulting from quarry blasting. Environ Earth Sci 74(4):2845-2860

20. Hasanipanah M, Shahnazar A, Amnieh HB, Armaghani DJ (2017) Prediction of air-overpressure caused by mine blasting using a new hybrid PSO-SVR model. Eng Comput 33(1):23-31

21. Hajihassani M, Armaghani DJ, Marto A, Mohamad ET (2015) Ground vibration prediction in quarry blasting through an artificial neural network optimized by imperialist competitive algorithm. Bull Eng Geol Environ 74(3):873-886

22. Ghasemi E, Ataei M, Hashemolhosseini H (2013) Development of a fuzzy model for predicting ground vibration caused by rock blasting in surface mining. J Vib Control 19(5):755-770

23. Saadat M, Khandelwal M, Monjezi M (2014) An ANN-based approach to predict blast-induced ground vibration of Gol-EGohar iron ore mine, Iran. J Rock Mech Geotech Eng 6(1):67-76

24. Duvall WI, Petkof B (1958) Spherical propagation of explosiongenerated strain pulses in rock. Bureau of Mines

25. Langefors U, Kihlstrom B (1963) The modern techniques of rock blasting. Wiley, New York

26. Ambraseys $\mathrm{N}$ (1968) Rock mechanics in engineering practice

27. Ghosh A, Daemen JJ (1983) A simple new blast vibration predictor (based on wave propagation laws). In: The 24th US symposium on rock mechanics (USRMS). American Rock Mechanics Association

28. Roy PP (1991) Vibration control in an opencast mine based on improved blast vibration predictors. Min Sci Technol 12(2):157-165

29. Ak H, Konuk $A$ (2008) The effect of discontinuity frequency on ground vibrations produced from bench blasting: a case study. Soil Dyn Earthq Eng 28(9):686-694

30. Simangunsong GM, Wahyudi S (2015) Effect of bedding plane on prediction blast-induced ground vibration in open pit coal mines. Int J Rock Mech Min Sci 79:1-8

31. Kumar R, Choudhury D, Bhargava K (2016) Determination of blast-induced ground vibration equations for rocks using mechanical and geological properties. J Rock Mech Geotech Eng 8(3):341-349

32. Murmu S, Maheshwari P, Verma HK (2018) Empirical and probabilistic analysis of blast-induced ground vibrations. Int J Rock Mech Min Sci 103:267-274

33. Zuo R (2017) Machine learning of mineralization-related geochemical anomalies: a review of potential methods. Nat Resour Res 26(4):457-464 
34. Moayedi H, Nazir R, Mosallanezhad M (2015) Determination of reliable stress and strain distributions along bored piles. Soil Mech Found Eng 51(6):285-291

35. Moayedi H, Mosallanezhad M (2017) Physico-chemical and shrinkage properties of highly organic soil treated with nontraditional additives. Geotech Geol Eng 35(4):1409-1419

36. Ruiseco JR, Williams J, Kumral M (2016) Optimizing ore-waste dig-limits as part of operational mine planning through genetic algorithms. Nat Resour Res 25(4):473-485

37. Moayedi H, Armaghani DJ (2018) Optimizing an ANN model with ICA for estimating bearing capacity of driven pile in cohesionless soil. Eng Comput 34(2):347-356

38. Moayedi $\mathrm{H}$, Mosallanezhad M (2017) Uplift resistance of belled and multi-belled piles in loose sand. Measurement 109:346-353

39. Tessema A (2017) Mineral systems analysis and artificial neural network modeling of chromite prospectivity in the Western Limb of the Bushveld Complex, South Africa. Nat Resour Res 26(4):465-488

40. Ford A, Miller JM, Mol AG (2016) A comparative analysis of weights of evidence, evidential belief functions, and fuzzy logic for mineral potential mapping using incomplete data at the scale of investigation. Nat Resour Res 25(1):19-33

41. Moayedi H, Mosallanezhad M, Nazir R (2017) Evaluation of maintained load test (MLT) and pile driving analyzer (PDA) in measuring bearing capacity of driven reinforced concrete piles. Soil Mech Found Eng 54(3):150-154

42. Carranza EJM (2018) Natural resources research publications on resourcing future generations, and introduction of papers in this special issue. Nat Resour Res 1-17

43. Moayedi $H$, Rezaei A (2017) An artificial neural network approach for under-reamed piles subjected to uplift forces in dry sand. Neural Comput Appl 1-10

44. Sheykhi H, Bagherpour R, Ghasemi E, Kalhori H (2018) Forecasting ground vibration due to rock blasting: a hybrid intelligent approach using support vector regression and fuzzy C-means clustering. Eng Comput 34(2):357-365

45. AminShokravi A, Eskandar H, Derakhsh AM, Rad HN, Ghanadi A (2018) The potential application of particle swarm optimization algorithm for forecasting the air-overpressure induced by mine blasting. Eng Comput 34(2):277-285

46. Faradonbeh RS, Armaghani DJ, Amnieh HB, Mohamad ET (2018) Prediction and minimization of blast-induced flyrock using gene expression programming and firefly algorithm. Neural Comput Appl 29(6):269-281

47. Nguyen $\mathrm{H}$, Bui X-N, Bui H-B, Mai N-L (2018) A comparative study of artificial neural networks in predicting blast-induced air-blast overpressure at Deo Nai open-pit coal mine, Vietnam. Neural Comput Appl 5:1-17. https://doi.org/10.1007/s0052 1-018-3717-5

48. Hasanipanah M, Naderi R, Kashir J, Noorani SA, Qaleh AZA (2017) Prediction of blast-produced ground vibration using particle swarm optimization. Eng Comput 33(2):173-179

49. Hasanipanah M, Faradonbeh RS, Amnieh HB, Armaghani DJ, Monjezi M (2017) Forecasting blast-induced ground vibration developing a CART model. Eng Comput 33(2):307-316

50. Armaghani DJ, Hasanipanah M, Amnieh HB, Mohamad ET (2018) Feasibility of ICA in approximating ground vibration resulting from mine blasting. Neural Comput Appl 29(9):457-465
51. Bakhtavar E, Abdollahisharif J, Ahmadi M (2017) Reduction of the undesirable bench-blasting consequences with emphasis on ground vibration using a developed multi-objective stochastic programming. Int J Min Reclam Environ 31(5):333-345

52. Bakhtavar E, Yousefi $\mathrm{S}$ (2018) Analysis of ground vibration risk on mine infrastructures: integrating fuzzy slack-based measure model and failure effects analysis. Int J Environ Sci Technol 1-12

53. Koçaslan A, Yüksek AG, Görgülü K, Arpaz E (2017) Evaluation of blast-induced ground vibrations in open-pit mines by using adaptive neuro-fuzzy inference systems. Environ Earth Sci 76(1):57

54. Nguyen H, Bui X-N, Tran Q-H, Mai N-L (2019) A new soft computing model for estimating and controlling blast-produced ground vibration based on hierarchical K-means clustering and cubist algorithms. Appl Soft Comput. https://doi.org/10.1016/j. asoc.2019.01.042

55. Nguyen H, Bui X-N, Tran Q-H, Le T-Q, Do N-H, Hoa LTT (2018) Evaluating and predicting blast-induced ground vibration in open-cast mine using ANN: a case study in Vietnam. SN Appl Sci 1(1):125. https://doi.org/10.1007/s42452-018-0136-2

56. Khandelwal M, Kankar P, Harsha S (2010) Evaluation and prediction of blast induced ground vibration using support vector machine. Min Sci Technol (China) 20(1):64-70

57. Khandelwal M, Kankar P (2011) Prediction of blast-induced air overpressure using support vector machine. Arab J Geosci 4(3-4):427-433

58. X-z SHI, Jian Z, B-b WU, Huang D, Wei W (2012) Support vector machines approach to mean particle size of rock fragmentation due to bench blasting prediction. Trans Nonferrous Met Soc China 22(2):432-441

59. Amini H, Gholami R, Monjezi M, Torabi SR, Zadhesh J (2012) Evaluation of flyrock phenomenon due to blasting operation by support vector machine. Neural Comput Appl 21(8):2077-2085

60. Nateghi R, Kiany M, Gholipouri O (2009) Control negative effects of blasting waves on concrete of the structures by analyzing of parameters of ground vibration. Tunn Undergr Space Technol 24(6):608-616

61. Cortes C, Vapnik V (1995) Support vector machine. Mach Learn 20(3):273-297

62. Basak D, Pal S, Patranabis DC (2007) Support vector regression. Neural Inf Process-Lett Rev 11(10):203-224

63. Xu S, Lu B, Baldea M, Edgar TF, Nixon M (2018) An improved variable selection method for support vector regression in nir spectral modeling. J Process Control 67:83-93

64. Alpaydin E (2009) Introduction to machine learning. MIT Press, Cambridge

65. Carver RH, Nash JG (2011) Doing data analysis with SPSS: version 18.0. Cengage Learning

Publisher's Note Springer Nature remains neutral with regard to jurisdictional claims in published maps and institutional affiliations. 